Newcomen Society was elected secretary. The committee has been asked to consider the questions of memorial services in Westminster Abbey, where there is a window to Trevithick, and at Dartford Church, in the grounds of which he was buried; a memorial lecture; the placing of tablets at Euston, where his engine "Catch-me-who-can" ran, on the site of his birthplace and at Penydarran, South Wales. It is also proposed to publish a memorial volume containing a good account of his life and work; no such work is at present available.

\section{The Electric Grid}

Prof. E. W. Marchant gave his presidential address to the Institution of Electrical Engineers on October 20. After discussing training and research he dwelt on the importance of some of the applications of psychology which enable men most suitable for special kinds of work to be chosen. For example, in direction-finding work in the Navy, it has been found possible to pick out men who can tell with high accuracy the direction from which a sound comes. Prof. Marchant went on to speak of the electric grid in Great Britain which has been in course of construction for the last four or five years and will be completed in a few months. The original eight year programme has been cut down by two years. The next stage in the development of electricity is the trading stage. Assuming that progress proceeds as rapidly as during the development of the grid, Great Britain will soon be completely electrified. Prof. Marchant divided the supply of electricity into three stages, generation, transmission and distribution. So far as generation is concerned, the range of possible improvements is now small. Similarly, great improvements have been made in the technical design of transmission lines. It is the final stage of the problem, namely, the distribution and utilisation of electrical energy, which offers the greatest scope. To do this successfully, there must be a great demand and the public must be educated so as to be ready to take full advantage of electricity for all kinds of purposes. He mentioned that in Germany electrical laboratories have been installed at small cost by manufacturers in all schools. These are equipped with electrical apparatus so as to familiarise the children with electrical heaters, cookers, kettles, irons, etc.

\section{Meteorological Effects during the Total Solar Eclipse}

Dr. C. F. Brooks, of the U.S. Weather Bureau, has given a brief preliminary account (Bull. Am. Meteorological Soc., Aug.-Sept. 1932, vol. 13, pp. 159160) of the co-operative effort made in the United States and eastern Canada to determine the effects upon the atmosphere of the total eclipse of the sun on August 31 last. The programme of meteorological observations was determined largely by the Blue Hill Observatory of Harvard University, but the scheme was carried out with the aid of many public bodies and private individuals. Special measurements were made of the radiation from sun and sky; conditions in the upper atmosphere were measured by meteorographs carried by aeroplanes and captive balloons; numerous ordinary meteorological observations were carried out by the regular observers of the U.S. Weather Bureau and by a large number of auxiliary voluntary observers.

THE large mass of observational material obtained in this way has still to be examined and discussed Dr. Brooks mentions, however, a few interesting facts that have already come to light. He suggests that the cloudy skies that spoiled the view of the eclipse for so many and interfered with the work of the astronomers, were far from being a drawback for the meteorological work. There were clouds at five different levels in parts of New England, and these included both stratiform and cumuliform clouds. Generally speaking, the cumulus clouds, which half covered the sky locally just before the eclipse, disappeared during the eclipse, as the cutting off of the main heat supply for the surface layers of the atmosphere checked convection, but the stratiform clouds higher up in some instances developed rapidly, so as to cause the sky to become completely overcast. Upward-flowing mountain breezes generally ceased, but, doubtless owing to the short duration of the period of reduced radiation, katabatic winds did not develop. The fall of temperature near the ground varied greatly, mainly owing to the changing amount of cloud : it ranged from $2^{\circ} \mathrm{F}$. to $11^{\circ} \mathrm{F}$., the latter figure representing the combination of two favourable factors-absence of cloud and sandiness of the soil, with its concomitant low specific heat. The publication of the more complete discussion of the observations will be awaited with interest by meteorologists.

\section{Elm Disease and its Distribution}

Fon the fifth year in succession the Forestry Commissioners have had a survey made on the status of the elm disease (Graphium ulmi). First observed on the Continent in 1919, and in England in 1927, the disease is now common throughout western and northern Europe, and more recently its occurrence has been noted on a few trees so far away as Ohio in the United States. In England between 1927 and 1931 it increased steadily both as regards the number of outbreaks and the damaging effect on the trees. The most notable feature in this year's survey is the reduced virulence of attack in nearly every area visited. It is quite impossible to say whether this diminution is merely a temporary check in the progress of the disease or the first sign of recovery. Elm bark beetles have long been suspected as being the principal means by which the disease is spread and this has now been proved to be the case. A great deal of work has been carried out in Holland on the relative resistance to attack of the various species of elms. So far only certain Asiatic species have proved immune and for the most part these are small trees unlikely to take the place of the English elm. All kinds of elms ordinarily planted in England appear to be susceptible; but, judging from the investigations conducted in Holland, there is some foundation for the hope that completely resistant forms of the common species may yet become available.

$$
\text { No. 3287, Vol. 130] }
$$

